\title{
Metode Antrian First In First Out Berbasis Website Pada Sistem Reservasi Gadget
}

\author{
Fhizyel Nazareta ${ }^{1}$, Iskandar Fitri ${ }^{2}$, Fauziah $^{3}$ \\ 1,2,3 Informatika, Fakutltas Teknologi Komunikasi dan Informatika, Universitas Nasional \\ e-mail: ${ }^{1}$ fhizyeln@gmail.com, ${ }^{2}$ iskandar.fitri@civitas.unas.ac.id, ${ }^{3}$ fauziah@civitas.unas.ac.id
}

\begin{abstract}
Abstrak
Sistem reservasi merupakan sistem untuk mengetahui informasi pelayanan jasa tertentu. Sistem reservasi service gadget ini bertujuan untuk memudahkan konsumen dalam melakukan pendaftaran atau reservasi karena dilakukan secara online, sehingga para konsumen tidak perlu menunggu untuk mengikuti antrian yang panjang saat reservasi manual. Oleh karena itu aplikasi ini dibuat dan diperlukan sebagai solusi dari masalah seperti antrian panjang saat reservasi secara komputasi berbasis website. Penerapan metode yang dilakukan dalam pembuatan sistem aplikasi service gadget ini, yaitu metode Antrian First In First Out yang menerapkan Single Channel-Single Phase. Pada aplikasi ini Konsumen melakukan reservasi antrian service pada halaman reservasi order service, setelah data terkirim selanjutnya akan diproses oleh sistem untuk di verifikasi. Setelah itu sistem akan menampilkan halaman bukti reservasi untuk dicetak oleh konsumen sebagai bukti sudah melakukan reservasi. Pengujian yang dilakukan melakukan perbandingan pada web browser seperti Microsoft Edge membutuhkan waktu 53 detik untuk melakukan reservasi dengan menjalankan aplikasi reservasi service gadget, sedangkan pengujian pada Mozilla Firefox 54 detik dan Google Chrome 58 detik. Selain itu dalam penggunaan memori (RAM) Microsoft Edge memakai 168,4KB, sedangkan pengujian pada Mozilla Firefox 212,6KB dan Google Chrome 274,0KB.
\end{abstract}

Kata kunci- Reservasi Service, Sistem Reservasi, Metode Antrian, Gadget, First In First Out

\begin{abstract}
Reservation system is a system to find out information on certain services. Service gadget reservation system aims to make easier for consumers to register reservations because it is done online, so consumers don't have to wait to follow long queues when making manual reservations. Therefore, this application was created and needed as a solution to problems such as long queues when making reservations on a web-based computing basis. The application of the method used in making this gadget service application system, namely the First In First Out Queue method which applies Single Channel-Single Phase. In this application, consumers make a service queue reservation on the service order reservation page, after data is send will then be processed by the system for verification. After system will view a reservation proof page to printed by consumers as proof of having made a reservation. The tests carried out made comparisons on web browsers such as Microsoft Edge it took 53 second to make a reservation by running the service gadget reservation application, while testing on Mozilla Firefox 54 second and Google Chrome 58 second. In addition, in usage RAM Microsoft Edge uses 168.4KB, while testing on Mozilla Firefox 212.6KB and Google Chrome 274.0KB.
\end{abstract}

Keywords - Service Reservation, Reservation System, Queue Method, Gadget, First In First Out 


\section{PENDAHULUAN}

$\mathrm{K}$ egiatan antrian dalam reservasi atau booking untuk keperluan memperbaiki gadget atau perangkat ponsel yang sedang bermasalah atau mengalami kerusakan, ini sudah menjadi kebiasaan dalam kegiatan reservasi dan secara langsung pada tempat yang menerima jasa untuk perbaikan perangkat ponsel pintar. Pokok permasalahan ada apabila konsumen menunggu lama dengan antrian yang panjang pada saat melakukan reservasi dan pendaftaran perbaikan atau service. Proses ini sangat kurang efektif jika dilihat dari segi waktu dan tenaga. Melihat kondisi seperti ini, aplikasi service gadget ini bisa digunakan untuk membantu dan meringankan konsumen dalam proses pendaftaran dan reservasi secara online dengan mudah.

Pada antrian service motor dapat menyebabkan konsumen merasa bosan dan juga dapat menyebabkan konsumen berpindah ke bengkel umum lainnya. Sehingga diperlukan rancangan sistem informasi metode antrian multiple channel berbasis web untuk membantu pelayanan yang bisa tertata dengan baik, sehingga harapan kepuasan konsumen akan terpenuhi dengan baik.[1]

Pemesanan tiket pesawat konsumen atau pelanggan bisa melakukan pemesanan tiket secara langsung datang ke kantor Bana Tour atau pelanggang bisa memesan melalui telepon dan pada bagian divisi tiketing akan melakukan pemesanan, menurut peneliti proses pemesanan tiket melalui telepon tidak begitu efektif dan efisien dilihat dari sisi waktu.[2]

Jasa reparasi sangat dibutuhkan karena rentangnya kerusakan pada barang elektronik tertentu. Namun konsumen atau pelanggan jasa reparasi memiliki keterbatasan akan infomasi mengenai penyedia jasa. Oleh karena itu pembuatan sistem informasi berbasis web merupakan solusi yang tepat karena dapat diakses secara cepat, online, dan kapan saja jika konsumen membutuhkan (realtime).[3]

Dari beberapa penelitian tersebut, maka dalam pengelola data pendaftaran atau reservasi yang sebelumnya dilakukan secara manual, tidak perlu dilakukan lagi karena akan memakan waktu yang sangat lama dan konsumen merasakan antrian yang sangat panjang. Untuk memecahkan masalah dan memberikan solusi yang baik dan efisien dapat dilakukan perubahan dari sistem yang sebelumnya secara manual menjadi terkomputerisasi.[4]

\section{METODE PENELITIAN}

Metode pengumpulan data dalam penelitian ini adalah metode FIFO (First In First Out) yaitu tahapan dalam penyelesaian masalah untuk melengkapi data penelitian yang dilakukan.

\section{$2.1 \quad$ Metode FIFO (First In First Out)}

Metode FIFO (First In First Out) adalah metode yang menerapkan dimana konsumen yang mendaftar atau melakukan reservasi terlebih dahulu akan mendapatkan giliran untuk dilayani terlebih dahulu. Sistem penerapan pada metode ini menggunakan garis tunggu (waiting line) yaitu pelanggang yang datang terlebih dahulu akan dilayani dan pelanggan lain menunggu giliran untuk mendapatkan pelayanan service.[5]

\section{1.1 Single Channel-Single Phase}

Jenis antrian ini menggunakan perapan sistem antrian Single Channel-Single Phase artinya dalam antrian ini hanya mempunyai satu jalur antrian dan terdapat satu jalur untuk fasilitas pelayanan (Server).[5] Antrian adalah proses dimana konsumen harus menunggu untuk mendapatkan pelayanan. Untuk meningkatkan performa dari metode antrian dengan ini menambahkan metode Single Channel-Single Phase, Sehingga jasa layanan dapatmelayani setiap pelanggannya dengan optimal sehingga pelanggan tidak perlu menunggu lebih lama dan 
tidak terjadi antrian yang panjang.[6] Pada metode Single Channel-Single Phase ini memeberikan gambaran atau solusi dari permasalahan yang ditemukan untuk meningkatkan kinerja pelayanan dalam proses reservasi service dengan menerapkan SCSP (Single ChannelSingle Phase) yang mempunyai satu jalur antrian dan satu jalur pelayanan service.[7]

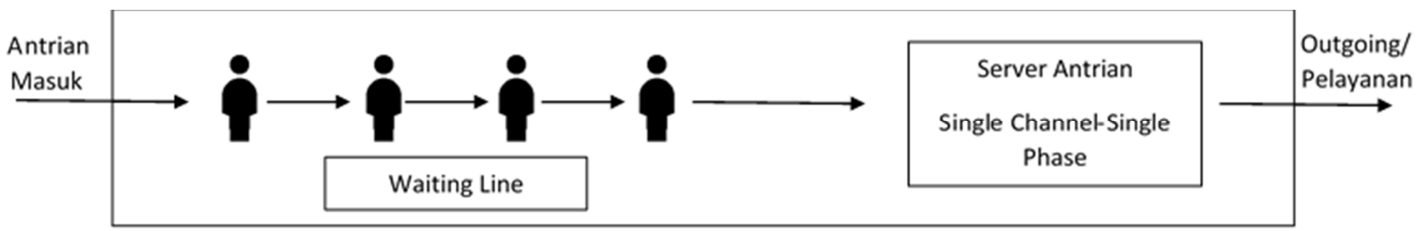

Gambar 1. Single Channel-Single Phase

\section{2 Waterfall Model}

Dalam pengembangan sistem juga menggunakan penerapan SDLC (software development life cycle) yaitu model waterfall karena pada penelitian ini membangun sistem reservasi dengan mengadopsi teknologi informasi.[8] Sistem reservasi ini cocok menggunakan metode ini karena kompleksitas dapat diprediksi dan mudah di analisa melalui metode ini. Waterfall model ini diterapkan untuk adanya sistem informasi yang jelas dan diharapkan proses penggunaan aplikasi ini menjadi semakin efektif dan efisien.[9]

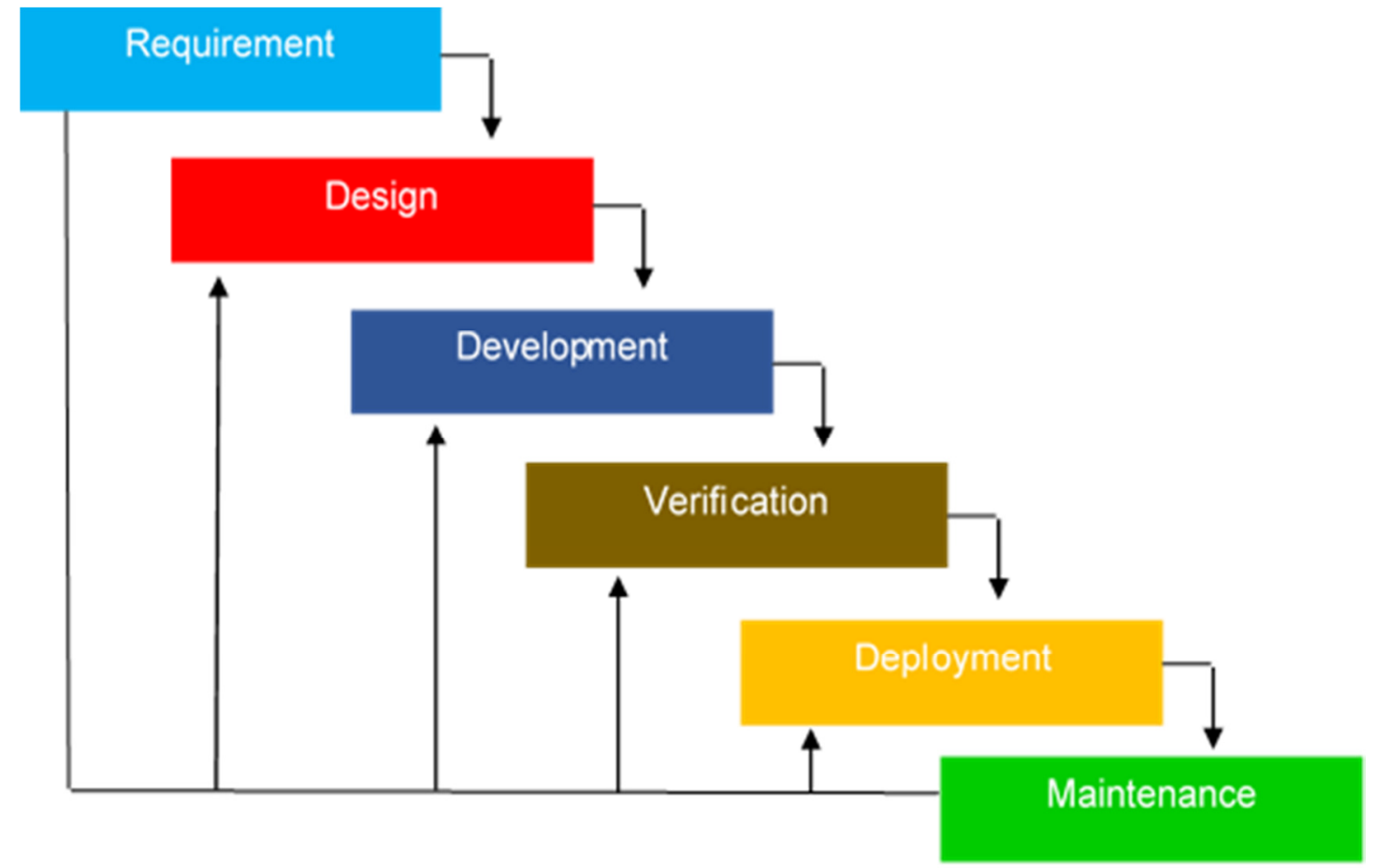

Gambar 2. Waterfall Model

\section{2.1 Requirement}

Tahap awal dari waterfall model adalah requirement. Dalam proses ini melakukan pencarian dari kebutuhan dalam pembuatan aplikasi, dimulai dari kebutuhan konsumen seperti pembuatan form untuk reservasi, cetak bukti reservasi, serta pemilihan bahasa pemrograman dan metode pemrograman yang digunakan, selain itu kebutuhan hardware dari pembuatan aplikasi reservasi ini harus diperhitungkan. 


\section{2.2 Design}

Tahap selanjutnya setelah requirement adalah tahap perancangan design aplikasi sebelum melakukan penerapan pembuatan aplikasi (coding). Pada proses ini diawali dalam pembuatan logo dan tampilan awal aplikasi yaitu landing page, halaman form untuk reservasi dan penerapan user interface lain agar memudahkan konsumen dalam penggunaan aplikasi.

\section{2.3 Development}

Tahap ketiga yaitu tahap pengembangan atau penerapan dari desain yang sudah dibuat menjadi aplikasi yang utuh melalui proses pengkodean sistem sehingga dapat dimengerti oleh mesin.

\section{2.4 Verification}

Tahap selanjutnya setelah Development atau penerapan aplikasi yaitu tahap verification yang bertujuan untuk melakukan pengujian pada sistem jika masih ada kekurangan atau error pada program aplikasi yang telah dibuat.

\section{2.5 Deployment}

Tahap selanjutnya setelah pengujian atau penerapan aplikasi yaitu tahap deployment yang bertujuan untuk melakukan penyebaran pada program aplikasi yang telah dibuat untuk digunakan user.

\section{2.6 Maintenance}

Tahap terakhir yaitu maintenance atau pemeliharaan dan perbaikan pada aplikasi yang sudah dilakukan tahap verivication atau pengujian error pada aplikasi yang sebelumnya masih ditahap pengembangan (development) untuk melakukan perbaikan dan penambahan fitur pada aplikasi sehingga dapat menuju tahap production selanjutnya untuk dapat digunakan user.

\section{HASIL DAN PEMBAHASAN}

Dalam penelitian ini Sistem Aplikasi Service Gadget terdiri dari beberapa aplikasi pengelola yaitu untuk reservasi konsumen dan halaman admin untuk mengelola data jasa layanan servis dan data reservasi konsumen. Aplikasi yang bersifat public dapat dipakai user untuk melakukan pendaftaran atau reservasi seperti mengisi formulir \& kendala kerusakan ponsel dan mencetak bukti reservasi setelah data diverifikasi oleh sistem. 


\section{1 Flowchart}

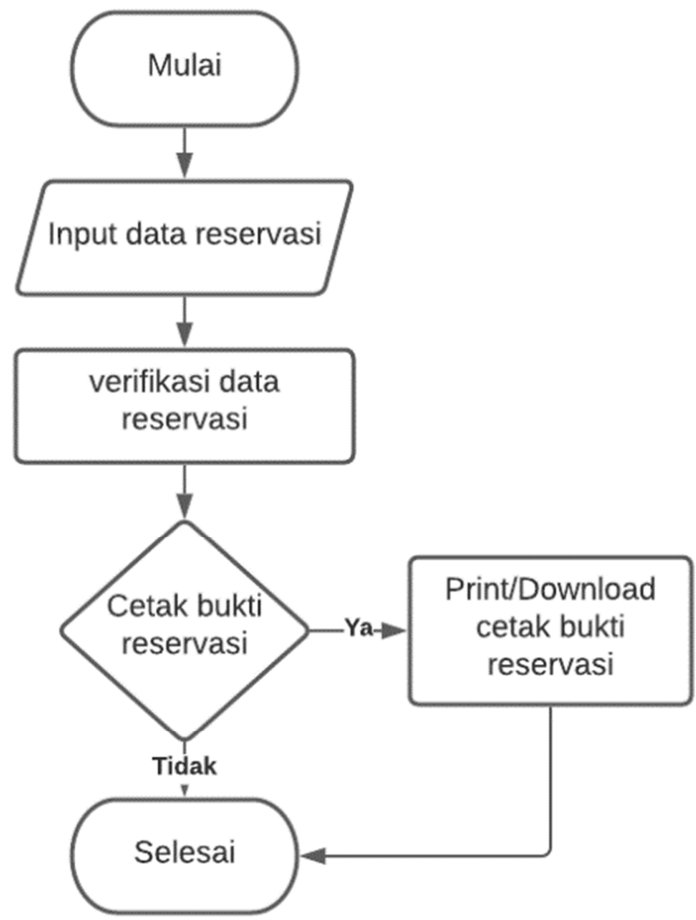

Gambar 3. Flowchart Reservasi

Pada sistem aplikasi reservasi service gadget dapat dilihat pada gambar 3 yang merupakan alur tahapan dari sistem aplikasi bekerja yang diawali dengan memulai untuk user menginput data reservasi kemudian melakukan simpan data dan data akan diproses verifikasi oleh sistem apabila belum ada data yang diisi maka sistem tidak akan menyimpan data reservasi. Kemudian setelah data tersimpan maka akan memunculkan hasil kondisi apakah user ingin mencetak bukti reservasi atau tidak, jika tidak maka user akan kembali ke halaman form reservasi, jika user memilih untuk mencetak bukti reservasi maka akan memunculkan data yang akan di generate menjadi file pdf untuk di cektak dan dibawa sebagai bukti reservasi ketika konsumen ingin melakukan service ponsel. 


\section{2 Use Case Diagram}

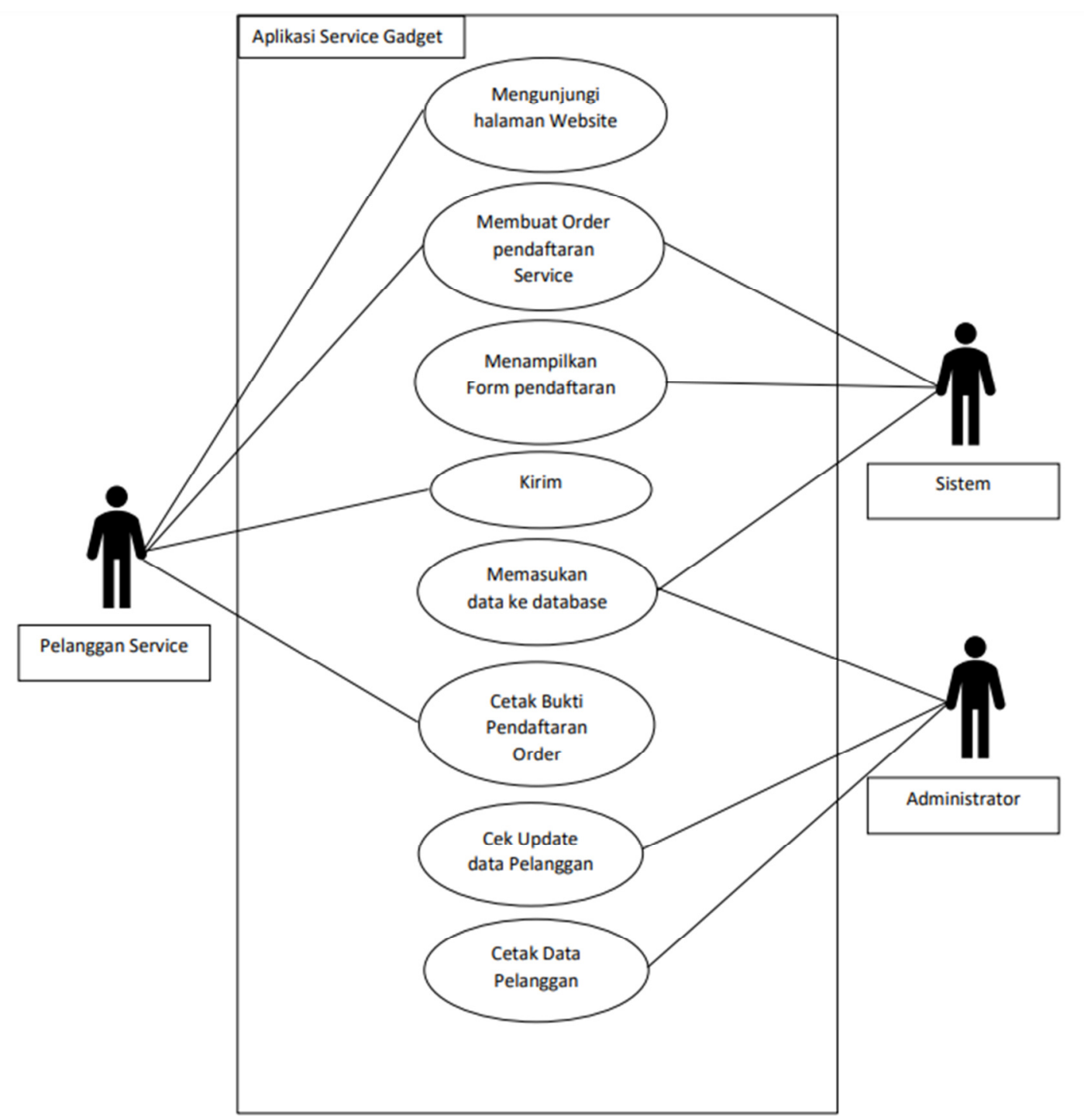

Gambar 4. Use Case Diagram

Use case diagram ini menjelaskan untuk penggunaan aplikasi yang akan dipakai oleh user dan berisi tahapan kegiatan kerja dari penggunaan aplikasi. [10] Use case menggambarkan bagaimana pelanggan bisa berinteraksi dengan sistem. Penggunan diawali dari actor yang berperan sebagai pelanggan service memasuki halaman awal website, kemudian membuat order dan melakukan reservasi pendaftaran setelah itu sistem akan menangani permintaan (request) dari pelanggan untuk mengirim hasil yang sudah verifikasi untuk ditampilkan kembali ke pelanggan (respon), setelah itu pelanggan dapat mencetak hasil dari tampilan bukti reservasi. Berikutnya setelah data berhasil masuk maka data akan diteruskan dan dikelola oleh actor yang berperan sebagai admin untuk melakukan pengecekan dan pengelolaan (update) data pelanggan sebagai bukti data pelanggan reservasi yang bisa dicetak dan direkap untuk riwayat bukti reservasi untuk perusahaan. 


\section{3 Tampilan Aplikasi Reservasi Service}

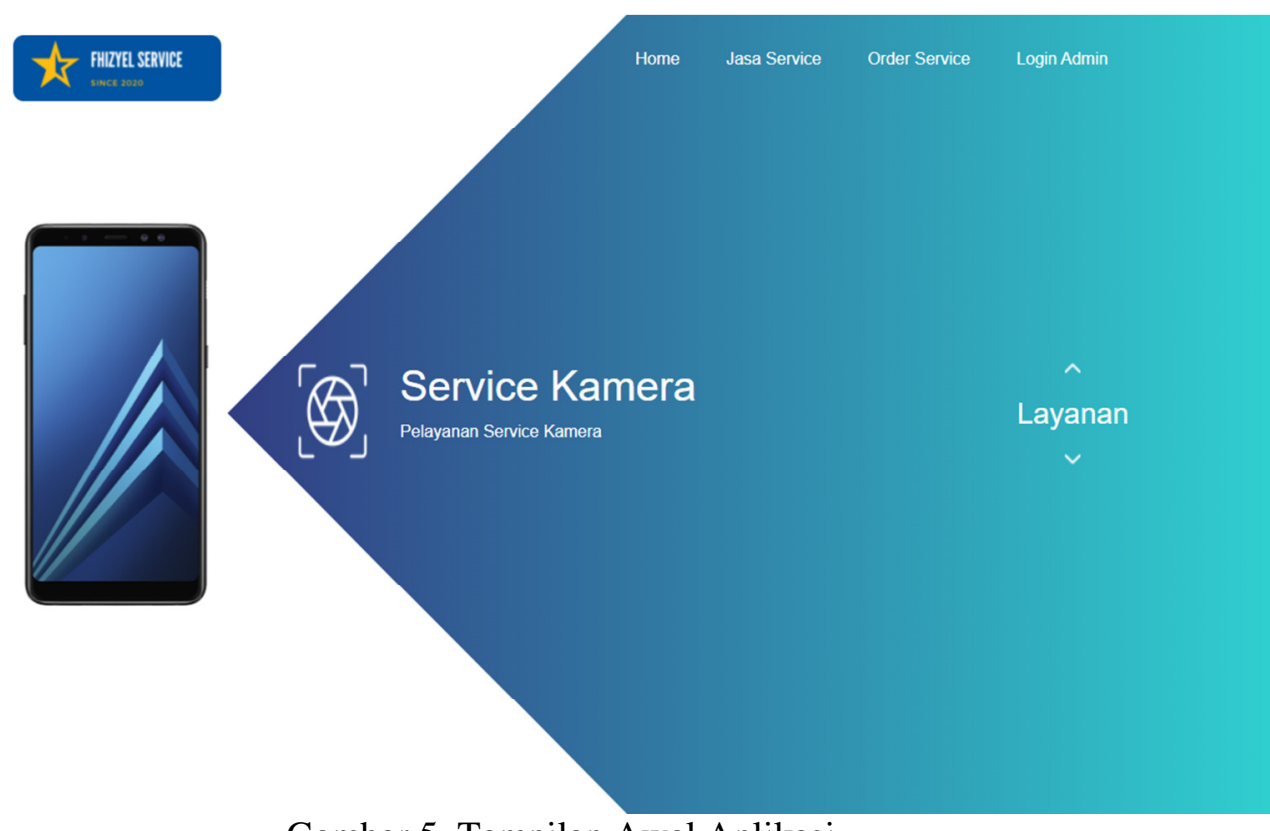

Gambar 5. Tampilan Awal Aplikasi

Tampilan pertama dalam aplikasi ini akan diperlihatkan tampilan landing page yaitu pada gambar 5 adalah halaman yang akan dilihat user pertama kali saat mengakses aplikasi service gadget.

\section{Kategori Layanan Jasa}

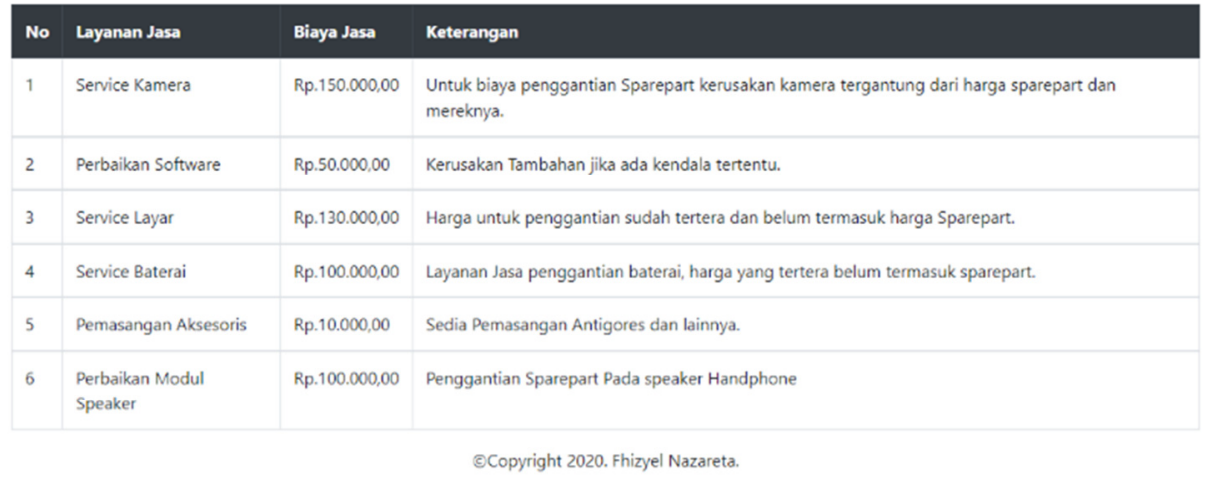

Gambar 6. Halaman Daftar Jasa Pelayanan

Pada gambar 6 merupakan halaman yang dapat dilihat user atau konsumen untuk melihat layanan apa saja yang diberikan dan keterangan harga pada kerusakan ponsel 


\section{Order Service Gadget}

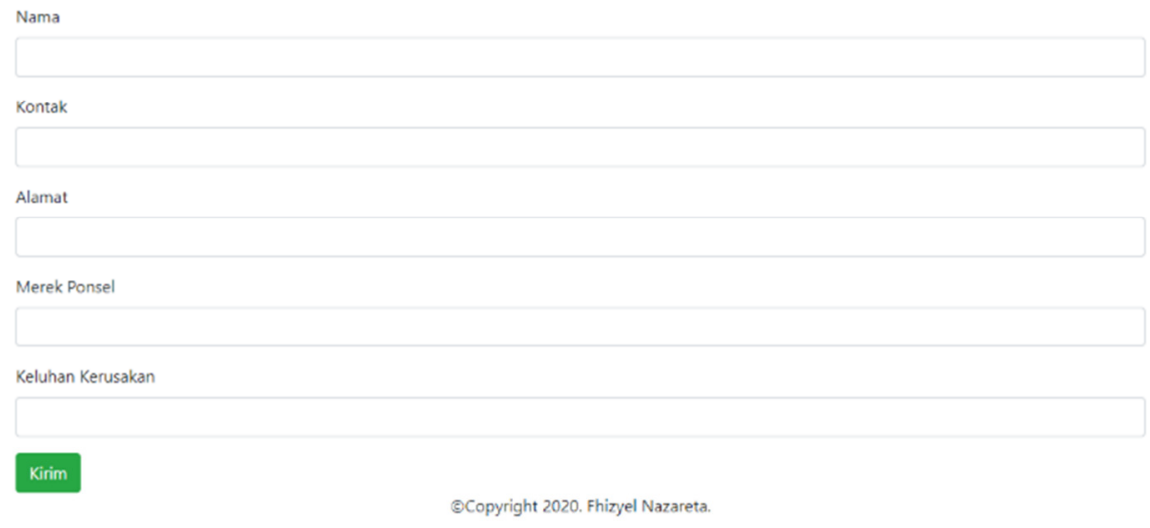

Gambar 7. Halaman Reservasi Service

Untuk melakukan reservasi atau order service konsumen harus mengisi formulir yang ada pada aplikasi yang bisa dilihat dari gambar 7. Pada halaman formulir ini konsumen harus mengisi dengan data yang benar serta mendeskripsikan keluhan atau kerusakan yang terjadi pada ponsel. Setelah melakukan pengisian data konsumen dapat mengirim atau menyimpan data reservasi yang sudah di isi dengan data yang sesuai keluhan dan kerusakan, dalam pengiriman data ini menggunakan metode POST agar data yang terkirim melalui form tidak terlihat pada $U R L$, setelah data di verifikasi oleh sistem data akan di simpan di server, maka data akan diteruskan ke admin untuk dikelola.

\section{Silahkan Masuk Sebagai Admin}

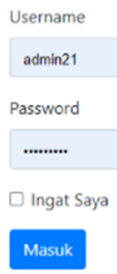

BCopyright 2020. Fhizyel Nazareta

\section{Gambar 8. Halaman Login Admin}

Pada aplikasi ini terdapat fitur halaman login admin agar data konsumen yang telah melakukan reservasi bisa dikelola oleh admin perusahaan jasa service. Tampilan halaman login dapat dilihat pada gambar 8 . 


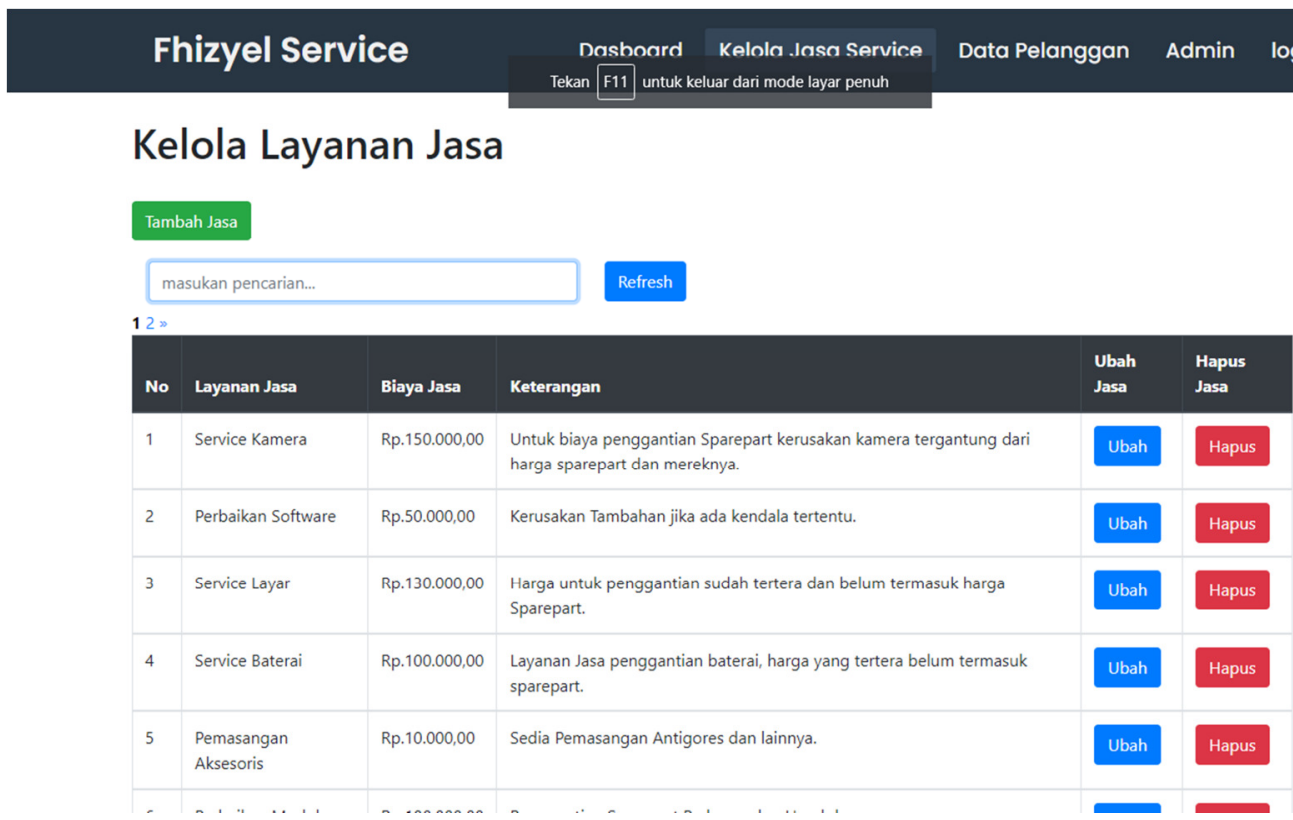

Gambar 9. Halaman Kelola Jasa Service

Pada gambar 9 merupakan tampilan halaman admin untuk mengelola jasa layanan yang bisa diupdate keterangan layanan dan harga jenis layanan, dan kategori atau jenis layanan bisa di tampilakan di menu bagian user pada halaman kategori jasa layanan servise pada gambar 6 .

\section{Fhizyel Service $\quad$ Dasboard Kelola Jasa Service Data Pelanggan Admin Logout}

\section{Daftar Pelanggan}

\begin{tabular}{|l|l|l|l|l|l|l|l|}
\hline Tambah Pelanggan Service & Cetak & & & & \\
\hline masukan pencarian... & & & & & \\
\hline
\end{tabular}

Gambar 10. Halaman Kelola Pelanggan

Pada gambar 10 adalah halaman daftar pelanggan yang sudah melakukan reservasi untuk service gadget, halaman ini dapat dikelola oleh admin untuk diupdate apabila konsumen salah dalam mengisi form pendaftaran service pada gambar 7. Admin dapat menghapus data 
reservasi pelanggan service apabila pelanggan sudah melakukan service ponsel atau melakukan pembatalan reservasi service.

\section{4 Pengujian Simulasi Reservasi}

\section{Order Service Gadget}

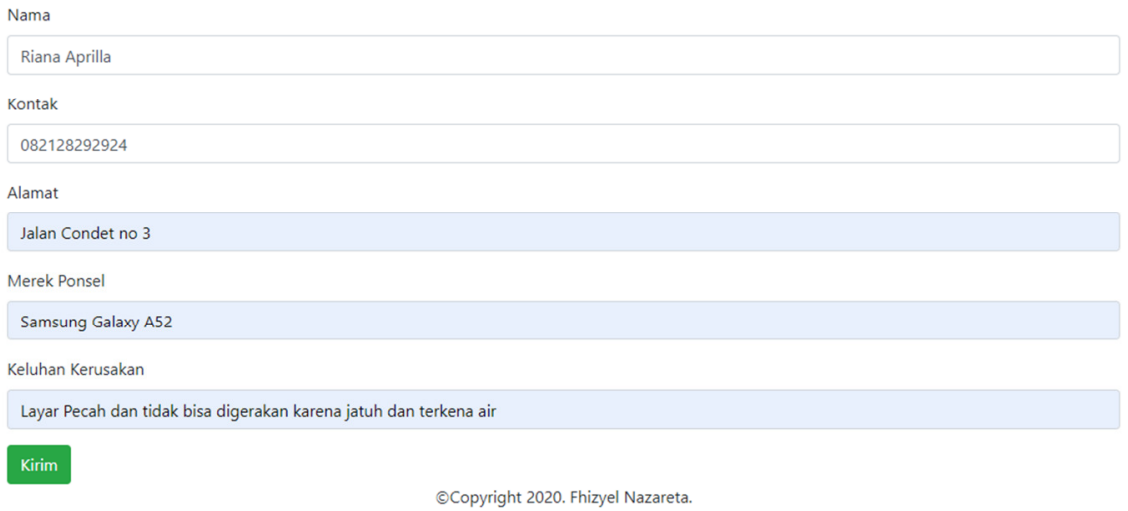

Gambar 13. Formulir Reservasi Service

Pada penggujian ini melakukan simulasi untuk proses reservasi yang dilakukan oleh konsumen. Pertama konsumen harus mengisi formulir yang ada pada aplikasi yang bisa dilihat dari gambar 13. Pada halaman formulir ini konsumen harus mengisi dengan data dengan benar serta mendeskripsikan keluhan atau kerusakan yang terjadi pada ponsel.

\section{Bukti Pendaftaran Service}

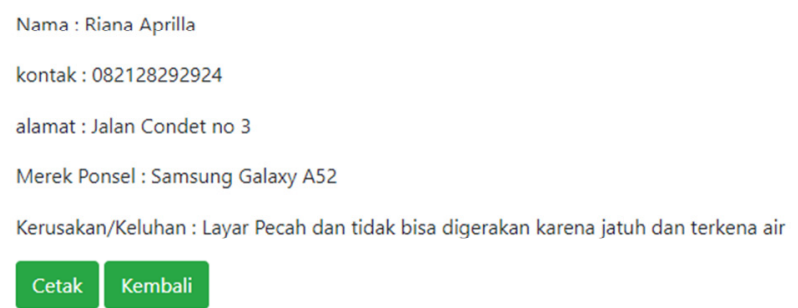

Gambar 14. Bukti Pendaftaran Reservasi

Setelah data berhasil diverifikasi oleh sistem dan berhasil disimpan ke server, sistem dari aplikasi service akan menampilkan data reservasi yang telah berhasi disimpan. 


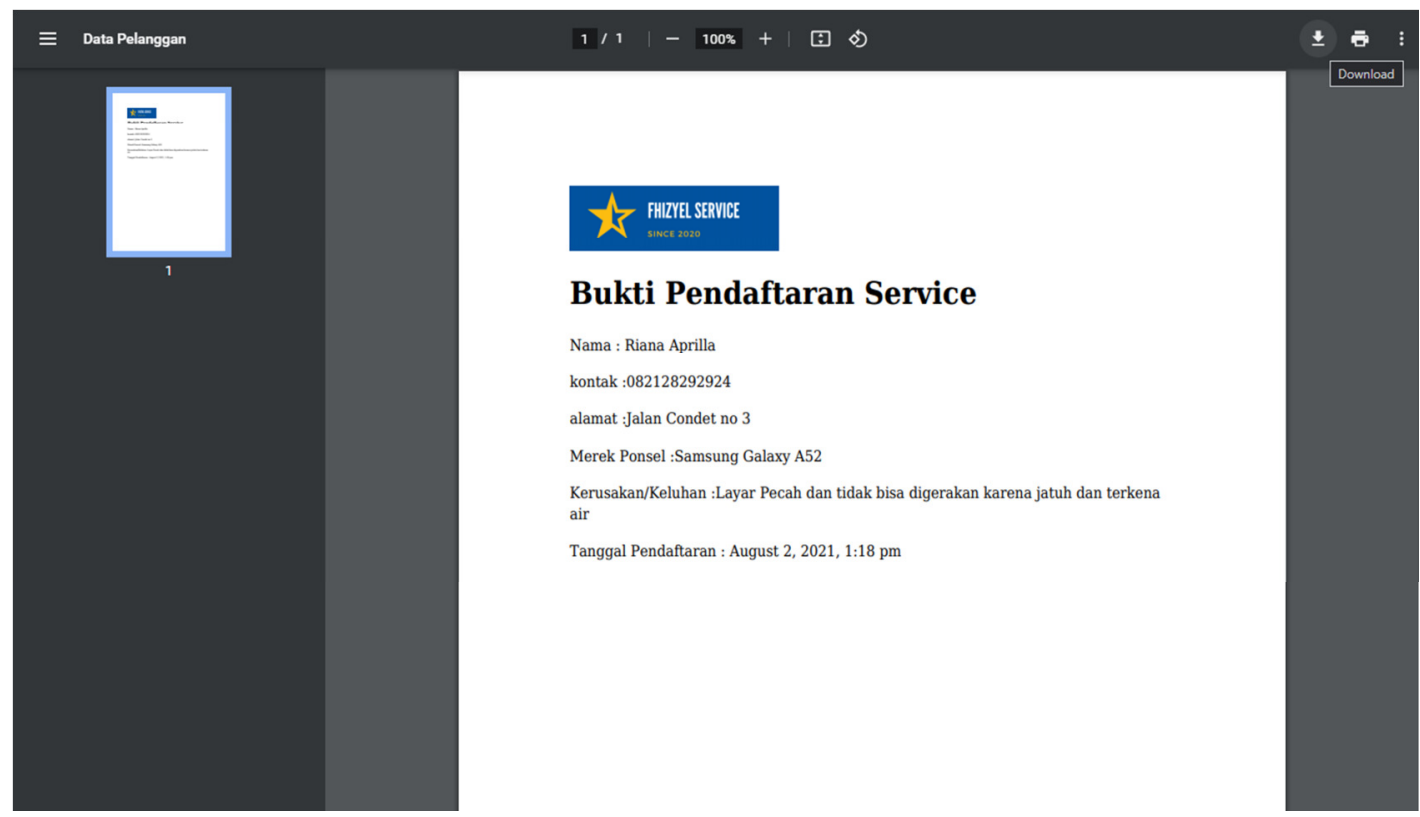

Gambar 15. Cetak Bukti Reservasi

Setelah menampilkan hasil data reservasi pada gambar 14, maka pengguna harus menekan tombol cetak agar data bisa digenerate ke file pdf untuk siap dicetak.

Pengujian terakhir dilakukan yaitu melakukan perbandingan penggunaan aplikasi pada web browser, dalam pengujian ini dilakukan perbandingan waktu proses penggunaan aplikasi untuk reservasi, mengetahui pemakaian $C P U$ dan pemakain memori sementara $(R A M)$.

Tabel 1. Perbandingan Waktu Proses Aplikasi pada Web Browser

\begin{tabular}{|c|c|c|c|}
\hline Web Browser & Waktu Proses & Status CPU & Pemakaian Memori RAM \\
\hline Google Chrome & 58 detik & $0 \%$ & $274,0 \mathrm{~KB}$ \\
\hline Mozilla Firefox & 54 detik & $0 \%$ & $212,6 \mathrm{~KB}$ \\
\hline Microsoft Edge & 53 detik & $0 \%$ & $168,4 \mathrm{~KB}$ \\
\hline
\end{tabular}

Dalam pengujian untuk menjalankan aplikasi menggunakan web browser dapat dilihat pada tabel 1, bila dilihat dari segi waktu dan kecepatan aplikasi lebih eifisien menggunakan web browser Chrome, sedangkan dengan penggunaan memori sementara $(R A M)$ lebih efisien dengan web browser Firefox dengan perbadingan yang tidak terlalu jauh dengan google chrome.

\section{KESIMPULAN}

Berdasarkan hasil penelitian dengan dibangunnya sistem aplikasi service gadget ini menggunakan metode antrian FIFO (First In First Out) yang dapat merubah sistem reservasi yang sebelumnya secara manual menjadi terkomputerisasi. Konsumen yang sebelumnya harus mendatangi tempat service secara langsung kurang lebih 1 jam, sekarang sudah dapat melakukan reservasi secara online membutuhkan waktu 53 detik, sehingga konsumen tidak perlu menunggu lama untuk mengikuti antrian yang panjang. 
Pada pengujian dalam menjalankan aplikasi direkomendasikan untuk menggunakan web browser Microsoft Edge, karena lebih ringan dalam penggunaan memori 168,4 KB untuk menjalankan aplikasi sehingga dapat lebih mempersingkat waktu dalam melakukan reservasi.

\section{SARAN}

Saran untuk penelitian selanjutnya dalam mengembangkan sistem aplikasi ini bisa ditambahkan fitur registrasi akun konsumen dan menu login untuk konsumen supaya bisa melihat riwayat transaksi dan reservasi yang bisa dipantau, sehingga dari segi kelayakan aplikasi akan bertambah dan memudahkan pelanggan dalam penggunaan aplikasi reservasi ini.

\section{DAFTAR PUSTAKA}

[1] Meryuni, M. Siddik, 2020, "Perancangan Sistem Antrian Booking Servis Menggunakan Multiple Channel Model Berbasis WEB,” Jurnal Mahasiswa Aplikasi Teknologi Komputer dan Informasi (JMApTeKsi)., Vol. 2, No. 2, pp. 1-16, [Online]. Available: http://www.ejournal.pelitaindonesia.ac.id/JMApTeKsi/index.php/JOM/article/view/591.

[2] N. A. Hidayah, N. Kumaladewi, S. Efrylla, 2010, "Sistem Informasi Pemesanan Tiket Pesawat Berbasis Web pada Bana Tour (PT. Wali Angkasamitra Utama)," Studia Informatika: Jurnal Sistem Informasi., Vol. 3, No. 1, pp. 134-138, doi: 10.15408/sijsi.v3i1.3007.

[3] D. Utami, F. Susanti, A. Sularsa, 2020, "Aplikasi Penyediaan Jasa Reparasi dan Penyewaan Alat Elektronik Berbasis Web," Vol. 6, No. 22, pp. 4141-4150, [Online]. Available:

https://openlibrarypublications.telkomuniversity.ac.id/index.php/appliedscience/article/vi ew/13687.

[4] N. Ruseno, R. Ahbati, 2020, "Rancang Bangun Aplikasi Pemesanan Tiket Umrah Menggunakan Algoritma First In First Out (FIFO) Berbasis Website," Journal Informatics, Science \& Technology Smtik Bani Saleh., Vol. 10, No. 1, [Online]. Available: https://jurnal.stmik.banisaleh.ac.id/index.php/JIST/issue/view/19.

[5] A. Andriyani, I. H. A. Amin, D. H. Untari N., 2019, "Sistem Informasi Reservasi Paket Wisata dan Paket Umroh pada Pt Pacific Tours Menggunakan Metode First In First Out (Fifo) Berbasis Web Mobile," SINTAK., Vol. 3, pp. 314-318, [Online]. Available: https://www.unisbank.ac.id/ojs/index.php/sintak/article/view/7605.

[6] D. A. Ramdani, W. Wahyudin, D. N. Rinaldi, 2021, "Model Sistem Antrian Menggunakan Pola Single Channel-Single Phase Dengan Promodel Pada Antrian Alfamart Unsika," SINTAK., Vol. 16, No, 1 pp. 13-24, doi: 10.33005/tekmapro.v16i1.191.

[7] Y. G. Nengsih, 2020, "Optimalisasi Antrian Menggunakan Metode Single Channel Single Phase (Studi Kasus DR. Reksodiwiryo Padang)," Jurnal Ilmiah Perekam dan Informasi Kesehatan Imelda (JIPIKI)., Vol. 5, No. 1, pp. 30-39, doi: 10.2411/jipiki.v5i1.356. 
[8] Sardiarinto, S. N. N. Alfisahrin, A. Andriani, 2015, "Rancang Bangun Sistem Reservasi Hotel Menggunakan Metode Waterfall," Jurnal Bianglala Informatika., Vol. 3, No. 1 pp. 50-57, doi: 10.31294/bi.v3i1.577.

[9] Y. Handriyanto, B. Sanjaya, 2020, "Model Waterfall Dalam Rancang Bangun Sistem Informasi Pemesanan Produk dan Outlet Berbasis Web," Jurnal Inovasi Informatika., Vol. 5, No. 2 pp. 153-160, doi: 10.51170/jii.v5i2.66.

[10] E. E. Gultom, D. Oktarina, 2019, "Rancang Bangun Sistem Informasi Pemesanan Antrian Service Mobil Berbasis Android," Jurnal Mahasiswa Aplikasi Teknologi Komputer dan Informasi (JMApTeKsi), [S.1.], Vol. 1, No. 1, pp. 58-64 [Online]. Available:

http://www.ejournal.pelitaindonesia.ac.id/JMApTeKsi/inex.php/JOM/article/view/393. 